\title{
LA INFLUENCIA AGUSTINIANA EN PEDRO ABELARDO
}

\author{
José de Jesús Herrera Ospina ${ }^{1^{*}}$ \\ Politécnico Colombiano Jaime Isaza Cadavid - Medellín
}

Proyecto de investigación que adelanto en el Politécnico con financiación de la institución. El proyecto se titula: "Algunos referentes conceptuales para establecer la relación entre cuerpo, estética y educación" y es financiado en su totalidad por el Politécnico Colombiano Jaime Isaza Cadavid.

\section{Resmmen}

La vida y obra del pensador escolástico Pedro Abelardo ha sido estudiada per se como el producto de una revolución cultural acaecida en el siglo XII, y que por muchos historiadores, ha sido llamado el Primer Renacimiento de Occidente. Se ha querido ver en Abelardo la imagen del libre pensador medieval, en sintonía más con el renacimiento moderno, que con su vinculación a la época histórica que vivió. Más aún, se ha hecho una escisión grande entre la patrística y la escolástica considerando ésta última como el producto de esa revolución antes mencionada. El propósito de este artículo es mostrar, precisamente, lo contrario: considerar a Abelardo como un pensador afianzado en su época, y con una profunda influencia del pensamiento patrístico, en especial de Agustín de Hipona. Para ello, se presentarán tres momentos de esta influencia: 1. La vida de Agustín y su incidencia en la de Abelardo: De las <Confessiones $>$ a la <Historia Calamitatum >. 2. La influencia de la teología patrística en la teología escolástica: Del <Si fallum sum > al <Sic et Non> 3. La filosofía moral: De la ética del $<$ Summum Bonum $>$ a la ética $<$ Nosce te ipsum $>$.

\section{Palabras clave}

Agustín, Abelardo, Conversión, Razón, Ingenio.

\section{THE AUGUSTINIAN INFLUENGE IN PEDRO ABELARDO}

\section{Abstract}

The life and work of the scholastic philosopher Peter Abelard has been studied per se as the product of a cultural revolution occurring in the twelfth century, and many historians, has been called the first Renaissance in the West. It wanted to see in the image of free medieval thinker to Abelard, more in tune with the modern renaissance, with its linkage to the historical age that he lived. Moreover, there has been a big rift between the patristic and scholastic considering the latter as the product of that revolution above. The purpose of this article is to show, precisely, the opposite: Abelard considered entrenched as a thinker in his time, and with a profound influence of patristic thought, especially Augustine of Hippo. To this end, there were three moments of this influence: 1. Augustine's life and its impact on the Abelard: From Confessions to Historia Calamitatum. 2. The influence of patristic theology in the scholastic theology: From < Si fallum sum $>$ to <Sic et Non $>3$. Moral philosophy: From $<$ Summum Bonum $>$ to $<$ Nosce te ipsum $>$

\section{Keywords}

Augustine, Abelard, Conversion, Ratio, Ingenious

\footnotetext{
1 Docente-Investigador de nacionalidad colombiana. Doctor en Filosofía de la Universidad Pontificia Bolivariana. Medellín -Colombia. Docente de tiempo completo de la Facultad de Ciencias Básicas, Sociales y Humanas del Politécnico Colombiano Jaime Isaza Cadavid, Medellín- Colombia y Catedrático de Filosofía Medieval del Instituto de Filosofía de la Universidad de Antioquia. E-mail: jjherrerao@elpoli.edu.co; joseherrera99@ hotmail.com. Este artículo de investigación filosófica, hace parte del proyecto de investigación: "Algunos referentes conceptuales cuerpo, estética y educación" de la Coordinación de Investigaciones del Politécnico Colombiano Jaime Isaza Cadavid
} 
1. La vida de Agustín y su incidencia en la de Abelardo: de las < Confessiones> a la $<$ Historia Calamitatum $>$

Abordar la vida y obra de Agustín de Hipona (354-430) es un tanto complejo, en cuanto, ello presupone una orientación histórica fundamental, que tiene como trasfondo el nacimiento del cristianismo romano y aquellos eventos acaecidos desde el paleo cristianismo hasta la caída del imperio por parte de los bárbaros comandados por Alarico en el año 410 . No obstante, nos atrevemos a presentar algunos momentos de la vida de este cristiano patrístico con el fin de mirar la incidencia de la misma en Pedro Abelardo (10791142), otro cristiano, correspondiente a la otra gran etapa del pensamiento medieval que denominamos Escolástica. Nuestro subtítulo muestra el itinerario nos desplazaremos desde las Confessiones hasta la primera carta de Abelardo que la tradición ha llamado <Historia Calamitatum>. Será una aproximación a dos momentos de la vida de Agustín, que creemos, se encuentran en perfecta sintonía con la de Abelardo y, que hipotéticamente, consideramos fueron influyentes en la vida del escolástico.

\subsection{Del uso de la costumbre al ingenio filosófico}

Agustín en el Libro I de sus <Confesiones $>$ relata con palabras muy dicientes su gusto primero por el conocimiento y su capacidad ingeniosa para acercarse a él:

Déjame, Dios mío, decir algo también del ingenio que me diste y de las fantasías en que lo estragaba. Me proponían como tema una tarea que inquietaba mi alma: si tenía éxito, conseguía el precio de la alabanza, de lo contrario, me aterraban la deshonra y los azotes. Tenía que recitar las palabras de Juno enojada y airada por no poder impedir la entrada de los troyanos en Italia.
Nunca me habían dicho que Juno dijera tales palabras, pero se nos obligaba a seguir y creer el vuelo de la fantasía de los poetas, repitiendo en prosa lo que él había dicho en verso. Y aquel hacía esto mejor y era más alabado que más vivamente representaba los efectos de la ira y del dolor, según la dignidad de la persona representada, y con las palabras vestía las sentencias que decía (Virgilio, Eneida, I, 37-49) ${ }^{1}$ (Agustín, 1993)

De una manera muy similar, relata también Abelardo su gusto por la filosofía y su renuncia a la vida militar. Afirma Abelardo en su <Historia Calamitatum > :

Fue tal mi pasión por aprender que dejé la pompa de la gloria militar a mis hermanos, juntamente con la herencia y la primogenitura. Abandoné el campo de Marte para postrarme a los pies de Minerva. Preferí la armadura de la dialéctica a todo otro tipo de filosofía. Por estas armas cambié las demás cosas, prefiriendo los conflictos de las disputas a los trofeos de las guerras. Así pues, recorrí diversas provincias, disputando. Me hice émulo de los filósofos peripatéticos, presentándome allí donde sabía que había interés por el arte de la dialéctica² (Abelardo, 1993)

Agustín habla del conocimiento centrado en la posibilidad de entender y exponer la poesía clásica y del arte empleado para alcanzar tal fin. Este arte en la tradición de las siete artes liberales se llama Retórica. Es de anotar que Agustín, a diferencia de Abelardo, fue un gran retórico, aunque posterior a su conversión, la considerará como mera charlatanería ${ }^{3}$. Por esto, las palabras subrayadas, muestran su interés por conocer: ingenio, "capacidad para inventar cosas o para pensar y hablar con gracia $(. . .)^{\prime \prime 4}$ Este ingenio es para Agustín un regalo de la divinidad. Su elocuacidad y capacidad eran puestas a prueba en el lugar donde tenía que presentarse. Por ello era: una tarea que inquietaba mi 
alma. Inquietud es un vocablo que entre otras cosas significa: "ganas de aprender cosas nuevas y de conocer a otras personas y lugares (...)" ${ }^{5}$ Eso era, lo que Agustín sentía, inquietud por conocer más allá de lo fáctico, lo perfectamente sublime. Más adelante, cuando convertido, exclama: “Dios nos hizo para Él, y nuestro corazón estará inquieto hasta que descanse en Él." (Agustín 1993). Además, con las palabras vestía las sentencias que decía, es decir, que era poeta. Algunos estudiosos han visto en la obra filosófica y teológica de Agustín, la poesía propia de los poetas clásicos romanos. En prosa expresaba lo que en verso se tenía como sagrado para los poetas. ${ }^{6}$ Es de anotar que Agustín tenía preferencia por el latín y no por el griego, como el mismo lo atestigua en sus Confessiones.

Por su parte, Abelardo, quien fue dialéctico y no retórico como Agustín, habla del mismo conocimiento desde la posibilidad de abandono de las artes de la milicia para una vida consagrada a la filosofía. De ahí que las palabras subrayadas nos lo muestran: pasión, es decir, "emoción, entusiasmo..."7 Es menester recordar que para un medieval, al igual que para un griego, el entusiasmo es estar prendido de Dios ( $/ n$ : en Theos: Dios). Minerva: configura la sabiduría, nacida de la cabeza de Júpiter, por ello, lo que Abelardo quiere es polemizar en la sabiduría, es decir, en Minerva (Atenea) y no guerrear en las huestes de Marte (Ares). Dialéctica: expresa lo propio de la filosofía, tanto que Agustín, dirá en sus Soliloquios:

R.- Ahora dime: ¿A qué arte corresponde definir, dividir y distribuir?

$A$.-Ya te he dicho que a la que regula los razonamientos.

$R$.-Luego la gramática ha recibido su ser de disciplina verdadera de la dialéctica, a la que has vindicado de todo reproche de falsedad, y esto no debe limitarse a la gramática, sino extender- se también a las demás artes liberales. Porque has dicho, y con verdad, que ninguna disciplina se dispensa de definir y dividir, y eso mismo le da la dignidad de tal. Si, pues, ellas son verdaderas por ser disciplinas, ¿Negará alguien que es la misma verdad la que hace- verdaderas a todas?

A.-Estoy por asentir a tus afirmaciones, pero me detiene el pensar que la misma dialéctica la contamos entre las disciplinas. Por lo cual, creo que gracias a aquella verdad, tiene razón de verdadera disciplina.

R.-Muy aguda es tu respuesta, pero con eso no niegas, según opino, que ella también es verdadera por ser disciplina.

A.-Es precisamente la razón que me hace fuerza, pues he advertido que es disciplina y, por eso, es verdadera.

$R$-Entonces, ¿Crees que ésta pudo ser disciplina por otra causa que por las definiciones y divisiones en ella introducidas?

\section{A. -Nada tengo que oponerte.}

$R .-S i$, pues, a la dialéctica pertenece tal oficio, es por sí misma disciplina verdadera. ¿Quién se maravillará, pues, de que aquella ciencia por la que son verdaderas las demás sea por sí misma y en sí misma la verdad verdadera?

A.-No hallo dificultad en admitir lo que dices. (Agustín 2009. II, XI)

Abelardo, es coherente con Agustín, volverse émulo de los peripatéticos es hacerse dialéctico. Agustín, recorrió como académico varias ciudades de África y Europa, a saber, Tagaste, Madaura, Cartago, Milán y Roma. Abelardo como dialéctico las ciudades francesas de París, Corbeil y Melun, entre otras. Pasaron del uso de la costumbre al uso de la razón, fueron liberales, ya que emplearon, el trívium para hacer posible, en un primer 
momento, su búsqueda de la verdad. Pero la verdad, tanto para Abelardo como para Agustín, no se limita a esto. Vayamos al segundo punto, para encontrar la otra cara de la misma.

\subsection{Del uso de los placeres a la visión beatífica}

Parafraseando a Michel Foucault, así podría ser considerada esta segunda influencia de la vida de Agustín en Abelardo. Del uso de los placeres se pasa a la visión de Dios, la vida en Dios. Ambos experimentaron en carne propia, el placer que da el cuerpo con toda la experimentación de los sentidos y ambos repudiarán su pasado carnal cuando son conversos. A Agustín, la conversio lo lleva a bautizarse, ordenarse sacerdote y consagrarse obispo, a Abelardo a convertirse en monje.

Agustín relata con gran pasión, lo que vivió en su juventud:

¿Y qué era lo que me deleitaba sino amar y ser amado? Pero mi amor iba más allá del mutuo afecto de dos almas, más allá del arco luminoso de la amistad. Del cieno de mi concupiscencia y del manantial de mi pubertad subían unas nieblas espesas que oscurecían mi corazón, ofuscándole de tal manera que no podía distinguir la clara luz del amor casto de la oscuridad de la lujuria. Amor y lujuria hervían juntos dentro de mí y arrebataban mi flaca edad por los despeñaderos de vanos deseos, anegándome en un mar de pecados. (Agustín, 1993)

Abelardo desde una experiencia relativamente similar a la de Agustín escribe:

Has de recordar, sin embargo, que la prosperidad hincha a los necios y que la tranquilidad mundana enerva el vigor del espíritu, que se disipa a través de los placeres de la carne. Creyéndome el único filósofo que quedaba en el mundo y sin tener ya ninguna inquietud, comencé a soltar los frenos de la carne, que hasta entonces había tenido a raya. Sucedió, pues, que cuantos más progresos hacía en la filosofía y en teología más comenzaba ahora a apartarme de los filósofos y los teólogos por la inmundicia de mi vida. (Abelardo, 1993)

Agustín y Abelardo, vivieron a plenitud la vida del placer corporal. Agustín refiere con lujo de detalles su vida mundana: la relación amistosa con sus amigos calaveras $^{8}$, afectiva con una mujer con quien tuvo a su hijo Adeodato ${ }^{9}$ y amistosaafectiva con un amigo que se convirtió en su más cercano confidente tanto que a su muerte sentirá la mayor tristeza y pesadumbre que hombre alguno pudiera sentir. ${ }^{10}$ Este amigo se convierte para Agustín en un motivo de conversión. Al relatar cómo enferma, mejora por un tiempo, recae de nuevo en la enfermedad y muere, alude a su propia vida, en donde caerá a lo más profundo de la mundanidad para posteriormente morir definitivamente a la concupiscencia y elevarse a lo más alto de la espiritualidad, primero bautizándose (junto con su hijo) ${ }^{11}$ luego ordenándose presbítero y, por último, siendo elegido Obispo de Hipona. Es de anotar que su conversión es gradual. Llega a pensar en su bautismo cuando lee las Cartas de Pablo y escucha a Ambrosio, Obispo de Milán. Sin desconocer el papel fundamental de su madre Mónica, quien muere viendo a su hijo convertido pero no viéndolo aún ordenado sacerdote ${ }^{12}$. De igual manera, Abelardo, encontrará en su relación con Heloísa, la expresión de su mayor mundanidad ${ }^{13}$ y la castración sufrida como la expiación a sus pecados cometidos $^{14}$. Cuando Abelardo narra la manera cómo sus enemigos le profieren tal castigo y cómo fueron los gemidos y lamentos de sus estudiantes y congéneres ante tal hecho, expresa, también de modo sorprendente, su conversión, que según él mismo, fue más motivada por la vergüenza que por una sincera vocación. 
“Confieso, que, en tanta postración y miseria, fue la confusión y la vergüenza más que la sinceridad de la conversión las que me empujaron a buscar un refugio en los claustros de un monasterio." (Abelardo, 1993). La mayor conversión en Abelardo radica en un abandono de su vida dedicada a enseñar a los pudientes y en ofrecer su sabiduría a los más necesitados. Se convertirá en un filósofo de Dios y no del mundo. Alejado definitivamente de los placeres carnales por la emasculación será un estudioso de la filosofía y teología.

\section{La influencia de la teología patrística en la teología} escolástica: Del <Si fallum $\underline{\text { sum}}>$ al $<$ Sic et Non $>$

Hablar de teología, tanto en la Patrística como en la Escolástica, es algo supremamente complejo, máxime si consideramos que para la época era la ciencia a la cual se dirigían todas las demás ciencias. ${ }^{15}$ La teología inicia, muy probablemente con los griegos, como respuesta a las narraciones de la mitología ${ }^{16}$, es decir, se racionaliza la idea de Dios con la llamada teología natural de los pensadores clásicos griegos: Platón y Aristóteles ${ }^{17}$. Pero se convierte en una ciencia del pensamiento racional con la presencia del cristianismo y los primeros teólogos patrísticos, tales como Justino y Tertuliano. Ahora bien, la presencia de Agustín como teólogo en el culmen de la Patrística es un hecho conocido. Inicia la validez de la teología como ciencia del pensamiento con Agustín y su famosa frase <Intelligo ut credam, credo ut intelligam $>^{18}$. Es la búsqueda de la intelección dentro de los asuntos propios del creer. La Biblia, palabra revelada por Dios, se alcanza a comprender no sólo por la fe, es necesaria también la razón para dirigirse. Claro está, la gracia manifestada en la fe, < regalo de Dios> es la base de la validez de la teología, pero no podría ser ciencia, si le falta la razón. Se podría decir, la teología es el estudio de Dios por medio de la razón humana. No obstante, para Agustín, la razón es limitada y tiene que supeditarse a los asuntos de la fe cuando se encuentra en dificultades. Por ello afirma en sus Cartas:

En vano oiríamos predicar cosas verdaderas si la fe no revistiese de piedad nuestro corazón antes de que la razón crítica nos haga ver que son falsas esas ficciones que abrigamos. La razón nos avisa desde fuera, mientras la verdad nos ilumina interiormente. La fe desempeña el papel que a ella le toca, y, gracias a esa preparación, la razón subsiguiente encuentra alguna de las verdades que buscaba. Luego a la razón falsa hay que interponerle, sin duda alguna, no sólo la razón verdadera, que nos hace entender lo que creemos, sino también la fe misma que tenemos en lo que no entendemos. Mejor es creer lo que es verdadero, aunque todavía no lo veas, que pensar ver lo verdadero cuando es falso. También la fe tiene sus ojos; por ellos ve en cierto modo que es verdadero lo que todavía no ve, y por ellos ve con certidumbre que todavía no ve lo que cree. En cambio, quien a través de la verdadera razón comprende lo que tan sólo creía, ha de ser antepuesto a quien desea aún comprender lo que cree. Finalmente, quien ni siquiera desea entender y opina que basta creer las cosas que debemos entender, no sabe aún para qué sirve la fe, ya que la fe piadosa no quiere estar sin la esperanza y sin la caridad. El creyente debe creer lo que todavía no ve, pero esperando y amando la futura visión. (Agustín 2009, CXX, 2. 8)

Ahora bien, la necesidad de racionalizar sobre Dios parte de un supuesto importante en la filosofía agustiniana, y es la constatación de la capacidad humana de dialectizar pero reconocer que existen límites profundos, tales como la existencia temporal y la propensión al error. Esta 
constatación, hace que Agustín se adelante a Descartes en la formulación de la duda metódica $<$ Si fallum sum $>$ y -tal como Abelardo, quien también reafirmará el carácter de la duda- propondrá que nada hay en el entendimiento humano que no haya sido puesto en duda y si uno se engaña quiere decir que se es.

\subsection{De Trinitate: Del conoci- miento humano fallido al conocimiento divino hallado}

Para adentrarnos al problema de la teología en Agustín, es menester abordar una de las obras más importantes del santo de Hipona. Hacemos referencia a su famosa obra De Trinitate o Tratado sobre la Santísima Trinidad. Allí, el lema "Si fallum sum" se puede rastrear en los siguientes apartes: Libro II, capítulo IX: Dificultades y soluciones. La verdad ha de buscarse en un estudio reposado. Libro IV, capítulo I: El conocimiento de nuestra miseria, escuela de perfección. Luz en las tinieblas. Libro V, capítulo IX: Impropiedad e indigencia del humano lenguaje. Libro X, capítulo VI: Juicio erróneo del alma acerca de sí misma. Libro XI, capítulo VIII: Razonamientos diversos. Imaginación y recuerdo. Es de anotar que sólo hacemos alusión a estos pasajes, pero con seguridad existen muchos más que dan cuenta de este problema acerca de la naturaleza del conocimiento humano en relación con el conocimiento de Dios, máxime en una obra que la componen quince libros.

A continuación, nos permitimos hacer una breve exégesis de cada uno de estos textos:

1) Libro II, capítulo IX: Dificultades $y$ soluciones. La verdad ha de buscarse en un estudio reposado: Este pasaje, por cierto, un tanto oscuro y polémico, plantea el asunto central de la Trinidad, la invisibilidad o no, la inmutabilidad o no y la inmortalidad o no del Padre, Hijo y Espíritu Santo y su epifanía en el mundo de los hombres. Es de anotar que el texto no resuelve sólo propone lo que hemos querido indagar en este estudio, a saber el si fallum sum a partir de la puesta en duda, si el Espíritu Santo al igual que el Padre y el $\mathrm{Hijo}^{19}$ tomaron cuerpo físico. Se inicia con una interpretación agustiniana de aquellos que comprenden que “(...) el Hijo es visible, no sólo cuando tomó carne mortal de una Virgen, sino ya antes, por sí mismo, pues Él, dicen se apareció los patriarcas." (Agustín, 1948) Lo que sigue a este texto muestra su sutileza teológica:

Y si se les replica: Si por esencia es el Hijo visible, también será mortal, porque del Padre sólo ha de entenderse que es el único inmortal; y si el Hijo es mortal por haberse encarnado, conceded, al menos, que sea también visible a causa de su encarnación. (Agustín, 1948)

Es la puesta en duda de la inmortalidad del Hijo y la afirmación certera de la inmortalidad del Padre, además la visibilidad total del Hijo por su naturaleza mortal y la invisibilidad de Padre por su naturaleza inmortal. Frente a esto ya aparece un primer atisbo de teología racional: El Hijo por su naturaleza humana es visible y mortal (otra cosa, se dirá después de su resurrección, pero esto es a posteriori) y el Padre por su naturaleza divina es invisible e inmortal. Ahora bien, la contraposición (muy al estilo como Abelardo lo abordará en sus obras) no se hace esperar:

El Hijo no se dice mortal por haberse humanado, porque ya antes era visible y mortal. Si dijesen que el Hijo era mortal a causa de su encarnación, entonces el Padre, sin su Hijo, ya no sería el único que posee la inmortalidad, porque el Verbo, por quien fueron hechas todas las cosas, es también inmortal. Al tomar carne perecedera no se despojo de la inmortalidad, puesto que ni el alma humana muere cuando el cuerpo fenece, según lo atestigua 
el mismo Señor, diciendo: No temáis a los que matan el cuerpo, porque no pueden matar el alma. (Agustín, 1948)

Esta oposición, por llamarla de alguna forma, es puesta en duda con la pregunta que sigue al texto: "¿Por ventura el Espíritu Santo tomó carne?" (Agustín 1948) Y responde el santo:

"Aquí sentirán, sin duda, mis adversarios cierta turbación. Si el Hijo es mortal por haberse encarnado, ¿Cómo afirma, excluidos el Hijo y el Espíritu Santo, que el Padre es el único inmortal, siendo así que el Espíritu Santo no tomó carne? Y si el Espíritu Santo no es inmortal, tampoco el Hijo es mortal por haberse encarnado; y si el Espíritu Santo es inmortal, ya no se dice del Padre solo que es el único inmortal." (Agustín 1948)

2) El capítulo 1 de Libro IV titulado <El conocimiento de nuestra miseria, escuela de Perfección, Luz en las tinieblas > nos imbuye en la problemática también presentada en De Civitate Dei, de las dos ciudades, que en franca lid, se le presentan al mundo exterior e interior del hombre creyente: la ciudad de Dios y la ciudad de los hombres. La ciudad de los hombres está representada en lo que él denomina las cosas mudables y la ciudad de Dios en lo que Ilama la Patria, es decir, el cielo. ${ }^{20}$

Además, la alusión al amor de Dios hacia nosotros considerándolo como el dador de toda gracia y bien, nos hace pensar en la historia de la salvación para el judeocristianismo, tanto que la cita bíblica del salmo citado da cuenta de la importancia que tiene para Agustín la gracia de Dios infundida sobre todos los hombres (creaturas). Posteriormente se refuerza con la cita paulina, de la sola gracia y fe: Cristo nos ha redimido con su sangre y con un precio de muerte (resurrección).

En el numeral 3, el texto cambia de tono y se convierte en algo más metafísico. Se habla de la inconmutabilidad de Dios, la unidad divina, la perfección de Dios. Con respecto al Verbo, se entiende todo desde la teología joánica del Verbo preexistente y por el que fueron hechas todas las $\operatorname{cosas}^{21}$. La influencia platónica, neoplatónica, (académica) ya vista en el estudio de las Confesiones es evidente: "porque también el alma es vida del cuerpo, pero es una vida creada, pues es mudable (...)" (Agustín, 1948)

En síntesis, este capítulo, con respecto al si fallum sum, es heredero de la doctrina dualista del neoplatonismo, claro está, con la plena influencia cristiana en donde tiene su razón de ser la tesis del santo de Hipona.

3) El libro V, capítulo IX: en este apartado Agustín, nos adentra al problema de la impropiedad e indigencia del lenguaje humano. Aquí el si fallum sum es evidente, la limitación humana está a flor de piel, máxime, si estamos en la tarea de demostrar la existencia de Dios, Uno y Trino. Empleará términos metafísicos para tratar de explicar nuestra insuficiencia para tal demostración, pero de todos modos muestra racionalmente los argumentos que llevarían a una eventual demostración de su existencia. La crítica a los herejes como Sabelio es latente, no obstante, se esfuerza en demostrar la incapacidad humana de la argumentación en la búsqueda de la definición teológica que en criticar las posiciones heterodoxas:

“(...) sin embargo, cuando se nos pregunta qué son estos tres, tenemos que reconocer la indigencia extremada de nuestro lenguaje. Decimos tres personas para no guardar silencio, no como si pretendiéramos definir la Trinidad." (Agustín, 1948)

4). El libro $X$, capítulo VI, titulado < Juicio erróneo del alma acerca de sí misma $>$, continúa en la línea del si fallum sum. El inicio es diciente: "Yerra, pues, el alma cuando se une a estas imágenes con 
amor tan extremado que llega a creerse de una misma naturaleza con ellas." (Agustín, 1948) Nótese que se habla del alma en relación con el cuerpo, esto nos da a entender que tanto la naturaleza física del hombre como su naturaleza psíquica están sujetas a error y, lógicamente, es la interioridad espiritual la que se da cuenta de tal asunto. Menester es, decir, que Agustín se refiere a un asunto, que en la modernidad con las escuelas: racionalista y empirista se trabajará con lujo de detalles, el asunto de la equivocación síquica frente a los fenómenos de la mente con respecto a los objetos, de la razón con respecto a la experiencia. Una gama de autores serán los que integrarán a sus reflexiones tal problemática: Descartes, Berkeley, Hume, serán los más importantes y que sobre ellos, recaerá toda una preocupación por explicar racionalmente los asuntos del creer humano en términos de actitud y conocimiento, entre otros. A propósito los estudios del mexicano Luis Villoro son significativos. ${ }^{22}$

Por último, el libro XI, capítulo 8, es el más extenso y complejo, pero importante para el estudio que nos ocupa. Allí, se encuentran enunciados una serie de términos complejos en la filosofía agustiniana: memoria, pensamiento, sensación, infinitud, unidad, percepción, visión, voluntad, imaginación, sensibilidad, corporeidad, verdad. Es toda una teoría del conocimiento para explicar la existencia de Dios, es la unión de la inteligencia, la voluntad y la imaginación. Es la memoria (Dios padre), la inteligencia o entendimiento (Dios Hijo) y la voluntad (Dios Espíritu Santo) lo que está en juego.

La limitación de este escrito radica en hallar esta problemática en el Sic et Non de Pedro Abelardo y máxime al no encontrar el texto traducido a nuestro idioma, no obstante, el principio de la duda es latente, si me engaño soy, si fallum sum. Veamos:

\subsection{El Sic et Non: La dialéctica al servicio de la teología}

La obra abelardiana Sic et $\mathrm{Non}^{23}$ constituye en la historia de la filosofía y teología medievales un asunto de reconocida importancia, tanto por el método empleado (Quaestio) como por la confrontación dialéctica que da paso a la teología racional propiamente dicha. No obstante, no es en la única obra donde plantea el asunto de la lógica en relación con la teología. En sus obras: De Trinitate et Unitate Divina, su Theologia Christiana y fundamentalmente en su obra: Teología del Sumo Bien, explana su capacidad dialéctica en los asuntos que atañen a la teología. Según Giovanni Reale y Antiseri (2007):

Una de las características de Abelardo es el uso de los instrumentos lógicos (en particular aristotélicos) para examinar puntos fundamentales de la fe cristiana. Mediante una cerrada y rigurosa confrontación con las opiniones de los adversarios, especifica en el lenguaje el espacio en que puede ejercitarse el trabajo del teólogo con la más completa autonomía. (p. 267)

En las anteriores obras, una preocupación al igual que la tuvo Agustín fue la explicación racional de la Trinidad Divina. $Y$ si bien, su explicación no es totalmente original, puesto que en su argumentación pareciera que hablarán los patrísticos, en especial, el santo de Hipona, sí es significativo su trabajo dialéctico para demostrar con argumentos racionales, valga decir, humanos, el mysterium fidei, que sabemos se trata de un tópico supremamente complejo.

El nombre Padre, como se dijo, designa el poder, el nombre Hijo, la sabiduría; el nombre Espíritu Santo el sentimiento de bondad hacia las creaturas. Determinaremos enseguida el fundamento de estos nombres, mostrando cómo, para indicar estas diferencias en Dios, éstas se usan en modo traslaticio respecto a 
su significado usual. Primero que todo mostramos que la distinción al interior de la Trinidad no tiene origen en Cristo, pero Él la enseñó con mayor claridad y precisión. La inspiración divina se ha dignado revelarla a los hebreos por medio de los profetas y a los paganos por medio de los filósofos, para animarlos, a través del conocimiento de la perfección del Sumo Bien, tanto a uno como a otro pueblo, al culto del único Dios "por quien existen todas las cosas" (I Co 8,6 ) y para que la fe en la Trinidad, en cuanto transmitida por los antiguos doctores, fuera acogida con mayor facilidad por ambos pueblos en el tiempo de la gracia (...) (Abelardo, 2007)

Podríamos sacar muchas cuestiones particulares de esta cita, a saber: el problema del lenguaje como asunto central de la dialéctica y de vital importancia en la aplicación teológica; la propuesta ecuménica o intercultural en el fondo de las religiones, llamadas en su tiempo, paganas. Pero es nuestro querer adentrarnos en algunos textos del Sic et Non para entender allí el asunto que hemos venido tratando en este acápite, el si fallum sum. Abordaremos cuatro textos cortos: El primero corresponde al capítulo VI intitulado: "Quod sit Deus tripartitus, et contra", el segundo, al capítulo XII "Quod in Trinitate alter sit unus cum altero, et contra", el tercero, al capítulo LXVIII "Quod Christus secundum carnem factus sit, et contra", y el cuarto, y último, corresponde al capítulo CXLVII nombrado: "Quod Cain non sit damnatus, et contra": Hacemos la aclaración de que no haremos ninguna traducción del texto sino una interpretación directamente el original latino. ${ }^{24}$

Primero que todo presentamos las generalidades de los textos, que también se convierten en las mismas de la obra Sic et Non:

1) La influencia de Agustín y de los Padres de la Iglesia: Se hace referencia, en el primero, al santo de Hipona; en el segundo, a Ambrosio, Jerónimo e Hilario; en el tercero, de nuevo a Agustín y Beda el Venerable; y, en el cuarto, de nuevo a Jerónimo y a Gregorio Nacianceno.

2) Se plantea el método escolástico, que será delineado totalmente por Tomás de Aquino en el siglo XIII, la Quaestio, con sus pro y contra.

3) El dominio de las citas bíblicas, en especial del Nuevo Testamento (Evangelios y Cartas Paulinas).

4) Dialéctica de los textos, es decir, no sólo lectura (Lectio) sino también debate, discusión e interpretación (Quaestio, Disputatio et Interpretatio).

Vayamos a los textos y su interpretación:

1) Quod sit Deus tripartitus, et contra: Augustinus in Enchirid. Cap IX: Satis est christiano rerum creatarum causam non nisi credere de bonitate Creatoris qui est Deus unus; nullamque esse naturam, quae non aut ipse sita ut ab ipso, eumque tripartitum, Patrem scilicet et Filium et Spiritum sanctum. Idem De Trinitate, lib. VIII, cap. VII: Non quoniam Deus Trinitas, ideo triplex putandus est; alioquin minor esset in singulis quam in tribus pariter. (Migne, 1885)

El texto que se va a interpretar es de Agustín, especialmente De Trinitate. En consonancia con el Santo de Hipona pone el interés en afirmar la denominación que se hace de Dios como Creador de todas las cosas y en poner en cuestionamiento si a este Dios Uno lo podemos también denominar Trino. Encontramos el contra y la disputatio al hacer énfasis en esta problemática de la Unidad y la Trinidad divinas. Pues así, como podemos llamar a Dios Padre, también lo llamamos Hijo y Espíritu Santo.

2) "Quod in Trinitate alter sit unus cum altero, et contra. Hymnus Am- 
brosianus ad tertiam: Nunc sancte nobis Spiritus, unus Patri cum Filio. Hieronymus in Epistola ad Galatas, lib. II: Qui cum secundum Deum unum sit ipse cum Patre, secundum mediatoris officium alius ab eo intelligitur. Hilarius De Trinitate, lib. I: de Patre loquens et Filio. Ut unum fide nostra si uterque non unus". (Migne, 1885)

Éste continúa en la línea del comentado anteriormente y toma para la discusión la definición de tres padres de la Iglesia sobre el asunto trinitario: Ambrosio, Jerónimo e Hilario. Los tres plantean el problema de la Unidad, (unus, unum), este es uno de los más fundamentales y polémicos frente a la definición de Dios Uno y Trino, si bien, la confrontación parece ser leve, de todos modos existe, y se rastrea más aún en la posición de Jerónimo cuando advierte sobre la comprensión (intelligitur) del tema en cuestión.

3) Quod Christus secundum carnem factus sit, et contra. Paulus in Epistola ad Romanos (I, 3): Quid factus est ei ex semine David secundum carnem. Augustinus contra Faustum: Christus, in quantum Deus est, omnia per ipsum facta sunt. In quantum homo est, et ipse factus est. Idem in lib. Quast. Veteris et novae legis, cap. LXX: Manifestum est Salvatorem non eguisse baptismo, quia Christus non factus sed natus est, dicente angelo pastoribus: Ecce natus est vobis hodie salvator, qui est Christus Dominus (Luc. II, 10). Beda super Lucam, homilía illius lectionis: Erat Jesus ejiciens daemonium: Misit Deus Filium suum factum ex muliere, factum sub lege (Gal. IV, 4). Neque enim audiendi sunt, qui legendum putant natum ex muliere, quia conceptus in utero virginali carnem non de nihilo, non aliunde, sed maternal traxit ex carne. (Migne, 1885)

Este texto retoma parte de lo descrito en los dos anteriores pero hace alusión específicamente al problema trinitario desde la figura de Cristo. Es de anotar que inicia con una alusión al texto de Pablo a los Romanos. Esto es significativo ya que la Patrística no se entenderá sin la referencia a Pablo y su incidencia sobre el helenismo. El naciente cristianismo entra en contacto directo con las culturas griega y romana y desde allí establece en algunos momentos un discurso coherente, en otros, disímil con la tradición filosófica y cultural de estos pueblos. El texto en cuestión plantea el asunto de la encarnación de Dios en la persona de Cristo. Agustín es claro en enfatizar que en Cristo fueron hechas todas las cosas, en cuanto Dios y en cuanto hombre. Y lo confirma con el relato del nacimiento de Lucas. Ahora bien, la afirmación de Beda el venerable es la que puede ponernos en el orden de la Quaestio al proponer que Cristo no fue engendrado de la nada pero si de la carne de una mujer, es decir, de un seno virginal.

4) Quod Cain non sit damnatus, et contra". Hieronymus Damaso: Sicuti ergo septima generatione Cain Peccatum est dissolutum, non judicabit quipped Dominus bis in idipsum, et qui semel receipt mala in vita sua, non eosdem cruciatus patietur in morte, quos passus est in vita, etc. Gregorius, Lib. VI Moralium: Vidi stultum firma radice et maledixi pulchritudini ejus statim (Job V, 3). Primus Cain civitatem construxisse scribitur, ut aperte monstrateretur, quia ipse in terra fundamentum possuit, qui a soliditate coelestis patriae alienus fuit (Migne, 1885)

Este texto, aunque se sale de los parámetros de los tres analizados anteriormente, presenta de nuevo la contraposición dialéctica con respecto a la figura bíblica de Caín, de quien se dice fue maldecido a errar por la tierra. Y la promesa divina, ante la preocupación de Caín por una muerte inminente, de pagar el precio de su sangre de quien lo hiciere hasta la séptima generación. Precisamente, el texto 
de Jerónimo al Papa Dámaso, confirma tal posición. Es de anotar que Jerónimo pasa a la historia de la patrística medieval como el gran traductor al latín de la biblia hebrea y griega. Ahora bien, el texto de Gregorio va en la línea de la explicación racional de por qué Caín construye en la tierra lo que no puede alcanzar en el cielo, es decir, una ciudad terrena y no eterna. Todo ello producto de la maldición de Dios.

Hasta aquí, el análisis del Sic et Non, en función de demostrar el método dialéctico en la teología medieval. Vayamos, finalmente, al último capítulo donde se mostrará la influencia agustiniana en Abelardo en los asuntos que atañe a la reflexión moral.

\section{La Filosofía Moral: de La Ética del "Summum Bonum" A La Ética del "Scito Te Ipsum"}

Los asuntos relativos a la filosofía moral en la Edad Media, los abordaremos en este artículo desde dos referentes: En la patrística, la obra agustiniana De vita beata y desde ésta conceptos claves como: sumo bien, voluntad y felicidad. En la Escolástica, la obra abelardiana Ethica, Scito te ipsum, donde aparecen conceptos tales como: intención, conciencia y voluntad. Para efectos de proponer la influencia de Agustín sobre Abelardo y las diferencias que también se derivan de ésta, analizaremos algunos de estos conceptos a la luz de las mismas obras.

\subsection{Sobre la vida Feliz: Una ética cristiana de acuerdo a la revelación}

La visión agustiniana sobre la moral se centra en la búsqueda de la felicidad desde una voluntad capaz de dirigirse al Sumo Bien. San Agustín parte de que la naturaleza humana está herida por el pecado original pero no destruida, la gracia de Dios la fortalece y le ayuda a alcanzar su fin mejor, pero ella conserva su capacidad de orientarse sola al bien. Prueba de ello, la encontramos en su obra Confesiones:

"iTarde te amé, hermosura tan antigua y tan nueva, tarde te amé! Tú estabas dentro y yo fuera, y fuera de mí te buscaba." (Agustín, 1993)

La ética agustiniana entra en consonancia con las éticas eudemonistas donde se persigue alcanzar algún bien. Por ello, según Agudelo Ramírez (2002):

“Desde Agustín, para vivir bien hay que hacer la voluntad de Dios, es decir, ha de realizarse lo que a Dios le agrada, como lo afirma con insistencia en su obra:

(...) todo el que vive bien hace la voluntad de Dios y todo el que hace su voluntad vive bien, ya que no hay otro modo de vivir bien sino hacer lo que a Dios le agrada, a no ser que os parezca de otra manera (Cfr. San Agustín, 1998).

Es de anotar que la reflexión agustiniana hace uso de la razón para cimentar la fe en el dato revelado. Se hace uso de la Ratio para cimentar la Fides. Es el InteIligo ut credam en todo su esplendor. Cosa contraria será en Abelardo, quien pondrá la Ratio sobre la Fides, con las consecuencias que ello tendrá para él, especialmente como piedra de toque para su condenación por parte del estamento eclesiástico.

Pero encontramos en el planteamiento agustiniano el mismo método que Abelardo utilizará en sus reflexiones morales $y$, en general, en todas sus reflexiones: la Quaestio. Esto se refleja en el siguiente diálogo:

Ahora os pregunto si Dios quiere que el hombre lo busque. Todos dijeron que sí. Pregunto: ¿Acaso podemos decir que el que busca a Dios, vive mal? -De 
ningún modo. Fue su respuesta. -Contestadme ahora una tercera pregunta: ¿El espíritu inmundo puede buscar a Dios? Todos contestaron que no, menos Navigio que dudaba, aunque al fin se unió a la opinión de los demás. -De este modo, el que busca a Dios cumple su voluntad y vive bien y no tiene el espíritu inmundo. Mas, el que busca a Dios todavía no lo posee. Por lo tanto, no todo el que vive bien hace lo que Dios quiere, ni quien carece del espíritu inmundo posee a Dios. Todos se rieron sorprendidos de las consecuencias deducidas de sus mismas concesiones. Mi madre, que había estado largo tiempo pasmada, me pidió que le explicara, ampliara y resolviera lo que necesariamente estaba distorsionado en lo dicho de la conclusión. Cuando lo hice, dijo: -Nadie puede llegar a Dios si no lo busca. -Perfecto, repliqué. Sin embargo, quien lo busca todavía no llega a Él, aunque viva bien. Así pues, no todo el que vive bien posee a Dios. -Mi madre contestó: Me parece que nadie posee a Dios. Lo que sucede es que a quien vive bien, Dios le es favorable; al que vive mal, le es hostil. -Entonces fue incorrecto haber afirmado ayer que es feliz quien posee a Dios, pues todo hombre tiene a Dios y, no obstante, no es feliz. -Ella insistió: Añade que lo tiene favorable o propicio. (San Agustín, 1998)

Aquí encontramos todos los elementos de la Quaestio: los interlocutores, las preguntas, la tesis controvertida, la disputa y la conclusión. Pero no es del interés ponderar sobre este asunto. Por ello, regresándonos al tema en cuestión, podemos afirmar que también vemos en este texto la reflexión moral en San Agustín, tal cual como se insinuaba al inicio de este apartado. -EI Sumo Bien, identificado en la búsqueda de Dios que, sin embargo, no es garan- tía de poseerlo, ya que nadie lo posee completamente, como se anota al final del texto, pero el Summum Bonum se identifica plenamente con la divinidad. - La voluntad humana, la cual debe ser reflejo de la voluntad de Dios, para ello, sólo cumple la voluntad divina quien busca vivir bien, esto es, en términos modernos, una estética de la vida ${ }^{25}$. La felicidad, la cual se alcanza cuando se llegue a la meta definitiva, el cielo, ya que no se posee a Dios definitivamente en esta vida, sino en la vida eterna. No obstante, es necesario buscarla desde esta vida para encontrarlos definitivamente en el más allá, como bien se puede rastrear en su obra al hablarnos de que el hombre alcanza la felicidad en la adquisición de la sabiduría:

Según San Agustín el perfecto conocimiento de Dios es el saber de tipo superior por el que se accede a la felicidad. En el desarrollo de su discurso insiste que la sabiduría coincide con dicho conocimiento, opuesto a la necedad insensata (...) El hombre feliz sería la persona moderada y sabia... Para Agustín quien pretenda ser feliz tiene que aspirar a bienes que siempre permanezcan y no le sean arrebatados por la fuerza. Para tal cometido propone que se haga la voluntad de Dios, en pro de obtener la anhelada felicidad. En este contexto, entiende que la práctica adecuada de las virtudes teologales cristianas facilita el acceso a una vida perfecta, como lo afirma con ahínco: “Esta es sin duda, la vida feliz porque es la vida perfecta. A ella, según presuponemos, podemos ser conducidos pronto, gracias a una firme fe, una alegre esperanza y una ardiente caridad" (Agudelo, 2002)

En Pedro Abelardo, encontraremos elementos similares a esta ética. Claro está, haciendo la salvedad que la herramienta con que se entablará la reflexión será la Ratio y no la Fides. 


\subsection{Nosce te ipsum o Scito te} ipsum: Una ética cristiana de acuerdo a la razón

Iniciamos esta última parte con un texto agustiniano que entra en completa sintonía con la ética abelardiana:

Sabido es que muchas veces los amigos nos pervierten con sus lisonjas, de la misma manera que los enemigos nos corrigen con sus insultos. Pero tú, Señor, les premias no atendiendo al bien que viene por ellos, sino a la intención con que lo hacen. (Agustín, 1993)

La ética de Abelardo está basada en la intención, en la recta conciencia y en la voluntad autónoma de obrar el bien y rechazar el mal. Por ello, es significativo para nuestra investigación encontrarnos con un texto como el citado. Aquí observamos la propuesta abelardiana en labios del santo de Hipona. La influencia agustiniana estaría justificada desde el texto, no obstante, no queremos afirmar tajantemente que es Agustín quien plantea en el ámbito cristiano una ética de la intención, creemos que es Abelardo el iniciador de esta reflexión, no obstante, es significativo que Agustín hiciera alusión a este asunto.

Sobre la ética en Abelardo y para dar razones de nuestro subtítulo, tenemos que considerar que es una reflexión de la moral cristiana de acuerdo con la razón. La ética agustiniana es una reflexión de la moral cristiana de acuerdo con la fe, con la revelación. Al contrario, Abelardo busca razones para entender los comportamientos del hombre, aunque sabemos que no deja de lado los asuntos de la revelación pero les da un nuevo sentido.

La moral de Abelardo es una moral de la intención. No es la acción la que cuenta, sino la intención, una intención buena, no aparente. Es necesario que el hombre no se engañe creyendo que el fin al que tiende es grato a Dios. La pura formalidad de la moral abelardiana, en la que algunos han visto la buena voluntad kantiana, se basa en el ámbito de las relaciones íntimas del alma con Dios. (Rodríguez, 1994)

Ahora bien, tales relaciones del alma del hombre con Dios (del animus con Deus), están orientadas desde una lógica racional. Por límites de este escrito, abordaremos los tres conceptos propuestos al inicio desde la lógica empleada de modo sucinto:

1) La intención:

“Llamamos buena, esto es, recta a la intención por sí misma. A la obra en cambio, la llamamos buena no porque contenga en sí bien alguno, sino porque nace de una intención buena." (Abelardo, 1994)

Racionalmente, nos encontramos ante una explicación fehaciente de la moral de la intención en contraposición a una moral establecida en la época, que se denomina moral de los resultados. No es la operatio sino la intentio la que racionalmente da sentido a lo que hacemos y de ahí que podamos considerar algo moralmente bueno o malo sólo desde la intención no desde el resultado.

2) La conciencia:

“(...) cuando no vamos contra nuestra conciencia, en vano debemos ser tenidos como reos de culpa ante Dios" (Abelardo, 1994).

Este es un asunto importante para el Abelardo y también lo fue para Agustín, con la salvedad de que el Santo de Hipona pone el acento en una conciencia objetiva, en relación más directa con el conocimiento de las cosas en Dios, mientras que Abelardo, se preocupa más en mostrar una conciencia subjetiva que parte del individuo y su intencionalidad. Recrea las palabras del apóstol Juan, cuando afirma que si la conciencia no nos condena 
tenemos plena confianza ante Dios. ${ }^{26} \mathrm{La}$ racionalidad se encuentra en la manera como aborda para el momento histórico el asunto relativo a la conciencia humana y cómo ella es el tamiz para juzgar cualquier acción buena o mala.

3) La voluntad:

Pecar por ignorancia es no ser culpable de algo, sino hacer lo que no se debe. Pecar con el pensamiento es querer con la voluntad lo que de ninguna manera se debe querer. Pecar de palabra y de obra es decir o hacer lo que no es conveniente, aunque suceda por ignorancia y contra nuestra voluntad (Abelardo, 1994)

El tema de la voluntad, al igual que el de la intención, es el más espinoso para dirimir las discusiones que se puedan presentar con relación a los actos morales ¿Cómo saber sí existe o no buena voluntad en una acción? ¿Mi voluntad es coherente con la voluntad de otros o con la misma voluntad de Dios? En Agustín, pareciera que el asunto de la voluntad se resolviera acudiendo al hecho de que debemos cumplir la voluntad de Dios en nuestra vida. Pero Abelardo, por el contrario, pareciera afirmar que es la voluntad propia frente a cada acción la que permite saber sí existe o no pecado. Según Rodríguez Santidrián (1994):

(...) La postura totalmente racional del maestro Abelardo hizo que recayera sobre ella la condenación del Concilio de Sens: "Cuanto se hace por ignorancia no debe atribuirse a culpa" (n. 10). "El hombre no se hace mejor ni peor por sus obras" (n. 13). "Ni la obra, ni la voluntad, ni la concupiscencia, ni el placer que le mueve es pecado, ni debemos querer que se extinga" (n. 19).

Con ello, no hay pecado en la voluntad sino voluntad pecaminosa, es decir, se puede tender al pecado desde la voluntad propia, pero en sí misma no constituye pecado, como no constituye pecado ni la obra-operatio-, ni el vicio-vitium-.

Hasta aquí la reflexión sobre los asuntos morales en la perspectiva abelardiana, reconociendo que si bien, faltarían por desglosar muchos más elementos unidos a la ética como el consentimiento, el pecado, el vicio, entre otros, nuestro interés consistió en observar cuáles de estos elementos seleccionados fueron ya presentados en la Patrística por Agustín y cómo se reflejaron en la Escolástica con Pedro Abelardo.

\section{Conclusiones breves}

La influencia agustiniana en Pedro Abelardo es notoria en los siguientes aspectos:

1) La vida en sus múltiples facetas: intelectual, pasional, religiosa, entre otras.

2) El empleo de la ratio en los asuntos de la fides. La filosofía al servicio de la teología.

3) La reflexión moral desde la búsqueda del sumo bien, la acción, la intención, la conciencia, la felicidad y la voluntad.

\section{Notas aclaratorias}

${ }^{1}$ El subrayado es nuestro.

${ }^{2}$ El subrayado es nuestro.

${ }^{3}$ A propósito los estudios de Gonzalo Soto Posada son importantes para una ampliación de estos conceptos.

${ }^{4}$ Voz: Ingenio.

${ }^{5}$ Voz: Inquietud.

${ }^{6}$ A propósito existen estudios que refieren la influencia de Agustín en la poesía española del siglo de oro. Cf (Morales Borrero1988).

${ }^{7}$ Voz: Pasión.

${ }^{8}$ En el libro III, 6 ss. Agustín relata su relación con los amigos, en especial, con los mencionados aquí. 
${ }^{9}$ Se puede rastrear el libro IV, 2 de sus Confesiones.

${ }^{10}$ Se puede rastrear el libro IV, 4 de sus Confesiones

${ }^{11}$ Se puede rastrear el libro IX, 6 de sus Confesiones

${ }^{12}$ Se puede rastrear el libro IX, 8 de sus Confesiones

${ }^{13}$ A propósito se puede confrontar la Historia Calamitatum o Carta consolatoria dirigida a un amigo en el capítulo 6.

${ }^{14}$ Confróntese el capítulo 8 de su Historia Calamitatum.

${ }^{15}$ Es de anotar, que las siete artes liberales (trívium: retórica, gramática y dialéctica; y, quadrivium: aritmética, geometría, música y astronomía) eran propedéutica para la filosofía y la teología. Algunos investigadores han querido probar la existencia de otros estudios dentro de las artes liberales, tales como la medicina, la ética, la economía y la política. Cf. (Bacigalupo 1990).

${ }^{16}$ Cfr. Homero y sus obras cumbres, Ilíada y Odisea. Y Hesíodo y su Teogonía.

17 A propósito encontramos en Platón los vestigios iniciales de la teología en su diálogo Eutifrón.

${ }^{18}$ Cfr. AGUSTíN. Sermón 43, 7-9. Este lema se convierte en el horizonte de todas las relaciones entre los ámbitos de la razón la fe en el Medioevo: Desde las discusiones de Juan Escoto Eriúgena en la época carolingia hasta las disputas de la Baja Edad Media con Guillermo de Occam y Duns Scoto.

${ }^{19}$ Es necesario dejar claro que cuando se hace referencia al Padre se está haciendo referencia al Dios creador, el Espíritu Santo como la fuerza emanada del Padre por medio de su Hijo, e Hijo, se debe entender por tal, al verbo encarnado de Dios, es decir, Jesucristo que según Juan I, I ss., existía antes que toda la creación. "Al principio existía la palabra y la palabra se dirigía a Dios y la palabra era Dios. Esta al principio se dirigía a Dios. Todo existió por medio de ella y sin ella nada existió de cuanto existe. En ella había vida y la vida era la luz de los hombres; la luz brilló en las tinieblas, y las tinieblas no la comprendieron. No era él la luz, sino un testigo de la luz. La luz verdadera que ilumina a todo hombre estaba viniendo al mundo. En el mundo estaba, el mundo existió por ella, y el mundo no la reconoció. Vino a los suyos, y los suyos no la acogieron. Pero a los que la recibieron los hizo capaces de ser hijos de Dios: a los que creen en él, los que no han nacido de la sangre ni del deseo de la carne ni del deseo del varón, sino de Dios. La palabra se hizo hombre y acampó entre nosotros. Contemplamos su gloria, gloria como de Hijo único del Padre, lleno de lealtad y fidelidad". Cf. (Biblia del Peregrino1995, 1852-1853.)

20 Ídem. Cfr. De Trinitate, IV, I, 2. Donde Agustín realiza toda una filosofía de la historia en clave cristiana.

${ }^{21}$ Cfr. Juan 1, 1.

${ }^{22}$ A propósito los estudios del mexicano Luis Villoro. Cfr. (Villoro 2006)

${ }^{23}$ Esta obra fue escrita aproximadamente en los años 1121-1122 muy probablemente después del famoso Concilio de Soissons, donde es condenada su obra sobre la Trinidad.

${ }^{24}$ Seguimos el texto de la Patrología Latina. Cfr. (Migne 1885).

${ }^{25}$ A propósito, las reflexiones filosóficas sobre este asunto se pueden ver en los estudios del medievalista Gonzalo Soto Posada ya mencionado.

${ }^{26} \mathrm{cfr} . \mathrm{I}$ Jn 3, 21

\section{Referencias}

ABELARDO, P. (1993). Conócete a ti mismo. Barcelona: Altaya.

ABELARDO, P. (2007). Teología del Sumo Bien. Citada por Reale, Giovanni y Antiseri

AGUDELO, M. (2002). El humanismo agustiniano en el diálogo "sobre la felicidad". Cuestiones Teológicas y Filosóficas. 29. No. 71: 113-122

AGUSTíN. (1993). Confesiones. Barcelona: Altaya.

AGUSTín. (1998) Sobre la Felicidad. Tr. Gonzalo Soto Posada. Medellín: Universidad Pontificia Bolivariana.

AGUSTíN. (2009). Cartas. Recuperado el 30 de Julio de: http://www.uned.es/ca-bergara/ppropias/miren/ simulacro07/texto_san_agustin.pdf

AGUSTíN. (1948). De Trinitate. En: Obras de San Agustín. 225. Madrid: Biblioteca de Autores Cristianos.

AGUSTíN. (2009). Soliloquios. II, XI. Recuperado Julio 20 de: http://www.augustinus.it/spagnolo/ soliloqui/ soliloqui $2 . \mathrm{htm}$. 
BACIGALUPO, L. (1990). Intención y conciencia en la ética de Abelardo. Lima: Fondo Editorial Universidad Católica.

BIBLIA DEL PEREGRINO. (1995). Bilbao, Ega-Mensajero. CARTAS DE ABELARDO Y HELOÍSA. (1993). Madrid: Alianza.

DARÍO. HISTORIA DE LA FILOSOFÍA 2. Patrística y Escolástica. Bogotá: San Pablo.

DICCIONARIO ESCOLAR DE LA LENGUA ESPAÑOLA. (1986). Bogotá: Santillana.

MIGNE, J.P. (1885). Patrologiae Latinae. Cursus completus. Tomus CLXXXVIII. París.

MORALES, M. (1988). Presencia de San Agustín en la poesía española del siglo de oro. Agustiniana. 29. No. 90: 685-724.

REALE, G y Antiseri, D. (2007). Historia de la Filosofía 2. Patrística y Escolástica. Bogotá: San Pablo.

RODRÍGUEZ, P. (1994). Estudio Preliminar a la obra de Abelardo, Pedro. Conócete a ti mismo. Barcelona: Altaya.

SOTO, G. (2007). Filosofía Medieval. Bogotá: San Pablo.

VILLORO, L. (2006). Creer, saber, conocer. México: Siglo XXI. 